\title{
Universal power converter for low power applications
}

\author{
M. Asna1, H. Shareef ${ }^{2}$, S. N. Khalid ${ }^{3}$, A. O. Idris ${ }^{4}$, A. N. Aldarmaki ${ }^{5}$, Basil Hamed ${ }^{6}$ \\ 1,2,5,6 Department of Electrical Engineering, United Arab Emirates University \\ ${ }^{3}$ Department of Electrical Power Engineering, Universiti Teknologi Malaysia, 81310 Johor Bahru, Malaysia \\ ${ }^{4}$ AADC-Al-Ain Distribution Company, United Arab Emirates
}

\begin{tabular}{l} 
Article Info \\
\hline Article history: \\
Received Mar 15, 2019 \\
Revised Jun 2, 2019 \\
Accepted Jul 13, 2019 \\
\hline Keywords: \\
Lightning search algorithm \\
Meta heuristics \\
Proportional Integral \\
Synchronous reference frame \\
Voltage-frequency converter
\end{tabular}

Article Info

Article history:

Received Mar 15, 2019

Revised Jun 2, 2019

Voltage-frequency converter

\begin{abstract}
A novel power converter that can perform both voltage and frequency conversion was proposed. Inappropriate power supply can damage sensitive sub-components and render the connected device inoperable. Henceforth, the proposed voltage-frequency converter acts as an interface to plug any electrical device directly into an electrical socket and provide the voltage and frequency required. The converter used a synchronous reference frame proportional-integral (SRFPI) controller to regulate the instantaneous output voltage and to improve steady state performance. Because the PI controller works together with the synchronous reference frame controller, it is difficult to tune the PI control parameters. To overcome this issue, a new meta heuristic optimization technique called lightening search algorithm (LSA) optimization was used to identify the optimum PI parameter values. A detailed description of the system operation and control strategy was presented. Finally, the performance of the converter was analyzed and verified by simulation and experimental results. The experimental result has shown that the proposed system has satisfactory output voltage and frequency under different input voltages.
\end{abstract}

Copyright @ 2019 Institute of Advanced Engineering and Science. All rights reserved.

\section{Corresponding Author:}

Hussain Shareef,

Department of Electrical Engineering, United Arab Emirates University, Al-Ain, 15551, United Arab Emirates.

Email: shareef@uaeu.ac.ae

\section{INTRODUCTION}

Voltage-frequency converters are becoming increasingly popular as most personal electrical devices are sensitive to the frequency and voltage specified on the device. For instance, a $60 \mathrm{~Hz}$ hair dryer can burn out on a $50 \mathrm{~Hz}$ electricity supply. Thus, the voltage-frequency converter can acts as an interface to plug any electrical appliance into a foreign electrical socket and ensure that the device works perfectly.

Previously, voltage and frequency conversion were performed using a transformer-based converter [1], as it has the advantages of simplicity and protection. However, it has some disadvantages such as increased power loss, high cost, and heavy weight. This work presents a transformerless power electronic based voltage-frequency converter for portable applications that has lower cost, smaller size, and lower power loss [2-3].

Figure 1 shows the general block diagram of the voltage-frequency converter. A rectifier converts the supply voltage into DC voltage and passes it to a DC-DC boost converter to step up the magnitude of voltage. The inverter converts the voltage back into an $\mathrm{AC}$ voltage and changes the frequency from $50 \mathrm{~Hz}$ to $60 \mathrm{~Hz}$ or vice-versa. In addition, a feedback PI controller circuit is used to regulate the load voltage and frequency. A low pass LC filter is used at the load side to eliminate high frequency components and hence improve the quality of the output voltage. 


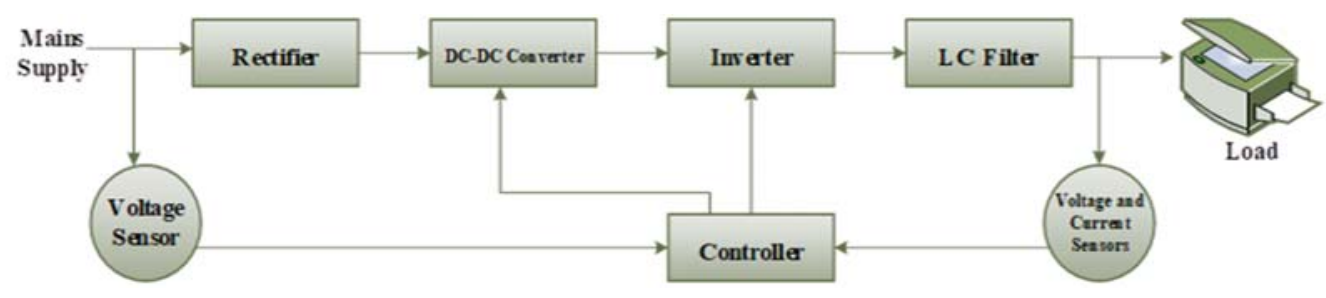

Figure 1. General block diagram of a voltage-frequency converter

The most challenging aspects for the realization of the proposed voltage-frequency converter are the design of the inverter controller and the tuning of the PI controller. Many advanced control methods were developed in recent years to find a solution to control the instantaneous output voltage and the frequency of the single phase inverter [4]. LC resonance control [5], dead beat control [6], sliding-mode control [7-8], and repetitive control [9] are a few examples; however, these control techniques are quite complex. In [10], a new controller based on the synchronous reference frame method is proposed for a single-phase sine wave inverter. The synchronous reference frame controller is widely used for three-phase applications; meanwhile, it is not well established for single -phase converters. It provides superior performance owing to the time-invariant nature of the controller, and thus the inverter control seems similar to a DC-DC converter [11-13].

The tuning of the PI controller is crucial for avoiding large variations in the control signal. Inappropriate selection of PI parameters makes the control loops operate inadequately, resulting in a low control performance [14]. Many tuning methods to estimate the parameters of PI controllers are available in literature; some of them are model based controllers [15], optimization tuning methods [16-18] and fuzzy logic controllers [19-20]. However, these methods generally do not guarantee a consistent, reliable, and robust optimal PI controller.

Therefore, in this work, a recent optimization method called the lightning search algorithm is used [21] to obtain the best PI parameters, namely proportional gain $\mathrm{k}_{\mathrm{p}}$ and integral gain $\mathrm{k}_{\mathrm{i}}$. LSA is a metaheuristic optimization technique based on the natural phenomenon of lightning, which originates from thunderstorms. Generally it provides better results compared to particle swarm optimization (PSO) with a great convergence rate [22].A detailed description of system operation and control strategy is presented in Section 2 . The inverter controller is described in Section 3. The performance of the converter is analyzed and hence verified by computer simulation and experimental results in Section 4. Finally, Section 5 presents the conclusions.

\section{OPERATION OF THE PROPOSED VOLTAGE-FREQUENCY CONVERTER}

The flowchart shown in Figure 2 describes the operation of the proposed voltage-frequency converter. It can be described using two different cases depending upon the magnitude of input voltage. Figure 3 shows the circuit diagram of the voltage-frequency converter.

Initially the supply voltage is sensed by a voltage sensor. In the first case, if the sensed voltage is equal to $220 \mathrm{~V} / 50 \mathrm{~Hz}$, it passes through the rectifier to convert the fixed frequency AC voltage into DC link voltage required for the inverter. The inverter then converts the unregulated DC link voltage back into an AC voltage of $110 \mathrm{~V}_{\text {rms }}$ and changes the frequency from $50 \mathrm{~Hz}$ to $60 \mathrm{~Hz}$ by using the synchronous reference frame PI (SRFPI) controller. The feedback controller maintains a constant load voltage via the proper tuning of the PI parameters by using the LSA optimization method [23]. An Arduino microcontroller board is used to generate the gate control signals to drive the inverter [24]. Finally, a low pass filter is connected at the load side to eliminate the high frequency components in the output voltage and thereby improve the output quality.

In the second case, i.e., if the supply voltage sensed is not equal to $220 \mathrm{~V} \mathrm{AC} \mathrm{(e.g.,} 110 \mathrm{~V} / 60 \mathrm{~Hz}$ ), then similar to the previous case, the rectifier performs DC conversion of the supply voltage and the inverter converts the DC link voltage back into $230 \mathrm{~V} \mathrm{AC}$ with a frequency of $50 \mathrm{~Hz}$. Unlike the first case, the boost converter is placed at the input side of the inverter to step up the rectified voltage to $400 \mathrm{~V}$ DC by varying the duty cycle. 


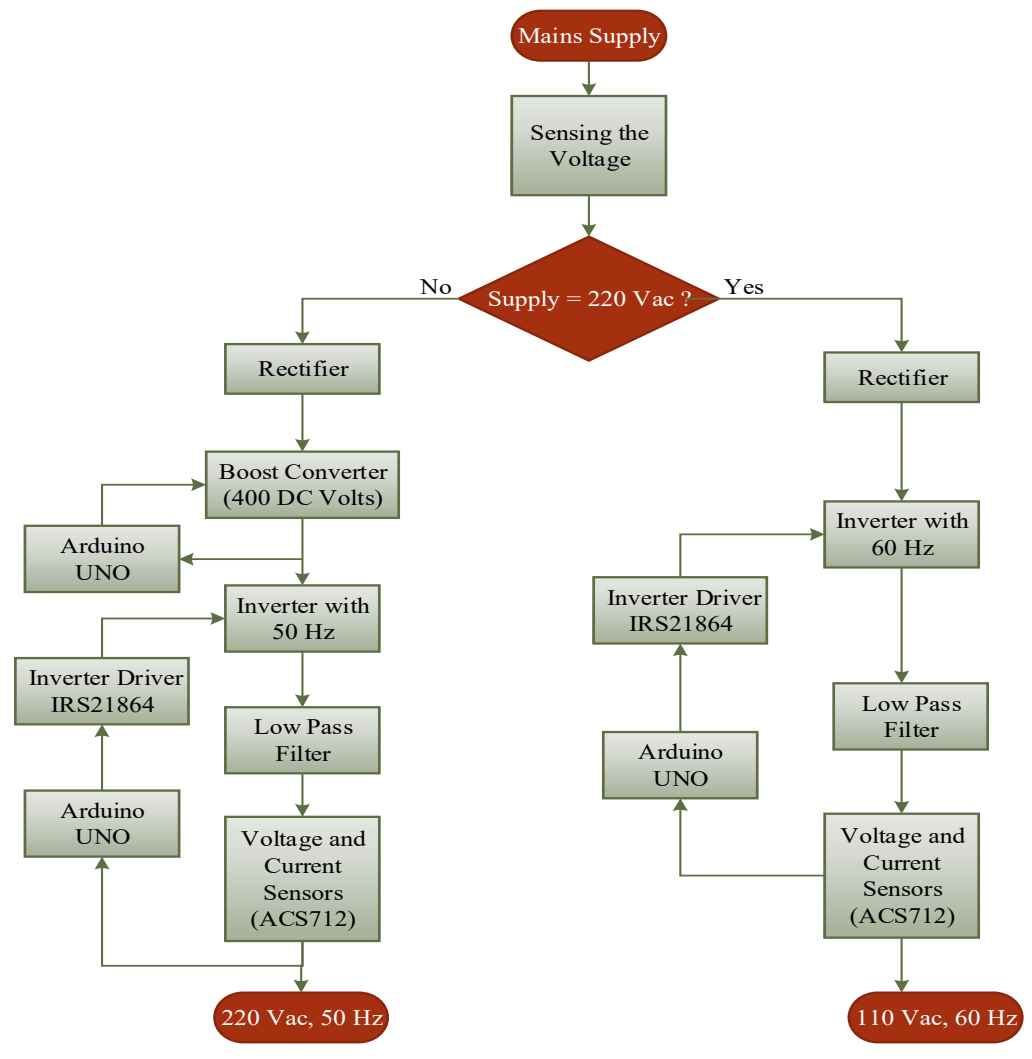

Figure 2. Flowchart of the proposed converter

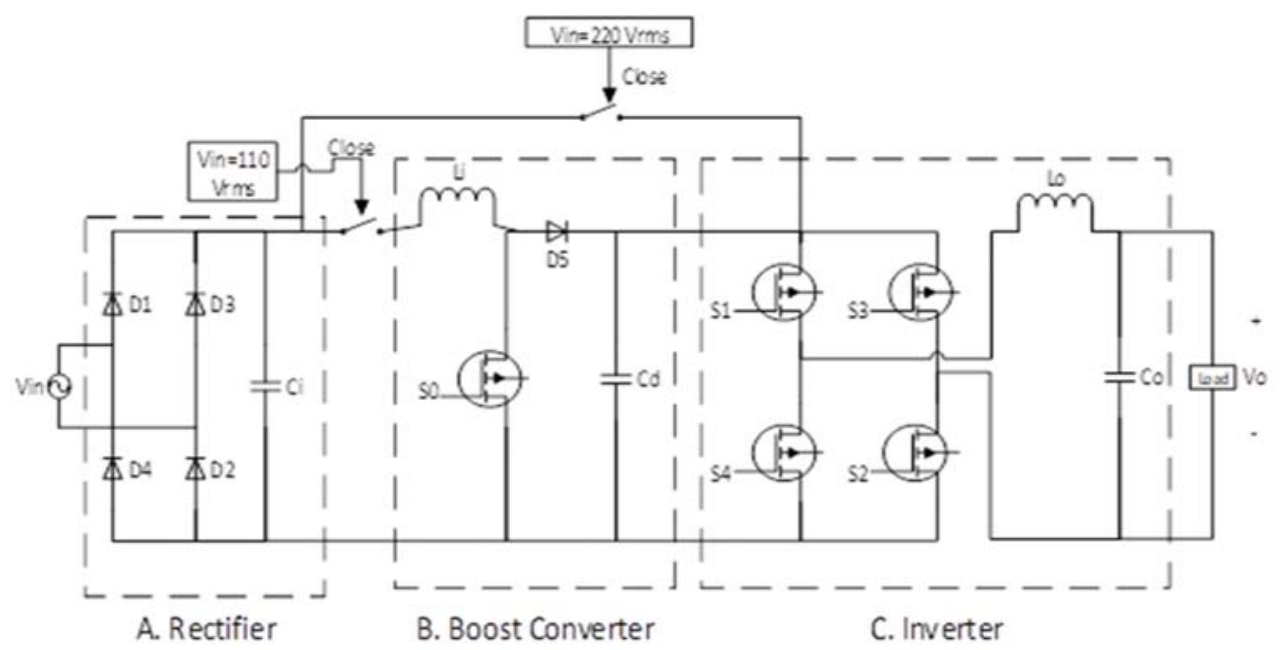

Figure 3. Circuit diagram of proposed converter

\section{INVERTER CONTROLLER DESCRIPTION}

Figure 4 illustrates the control scheme used in the proposed voltage-frequency converter. It includes an SRFPI controller to regulate the instantaneous output voltage, and an inner current loop and an outer voltage loop with a PI controller to improve both transient and steady-state performances, thereby improving 
system robustness [25]. The reference signal for the inner loop is the output signal of the voltage loop. Feedback signal capacitor current and output voltage are given for the inner and outer loops, respectively. Because the capacitor current is directly proportional to rate of change of output voltage for any slight distortion in output voltage, the inner control loop performs faster and compensates the error. For a single phase system, a Park transformation for obtaining the variables in a synchronous (DQ) reference frame is given in Equation 1.

$$
\left[\begin{array}{l}
V_{d} \\
V_{q}
\end{array}\right]=\left[\begin{array}{cc}
\cos \omega t & \sin \omega t \\
-\sin \omega t & \cos \omega t
\end{array}\right]\left[\begin{array}{l}
V_{\alpha} \\
V_{\beta}
\end{array}\right]
$$

The PI parameters in the voltage and current controllers are tuned by the LSA optimization technique. Similar to other metaheuristic algorithms, the LSA requires a population to initiate a search. It considers the involvement of fast particles known as projectiles to perform unique exploration and exploitation activities and search for the optimum solution. The tuned PI controller parameters $\left(\mathrm{k}_{\mathrm{p}}\right.$ and $\left.\mathrm{k}_{\mathrm{i}}\right)$ based on the LSA optimization technique can yield a better disturbance rejection compared to other conventional techniques.

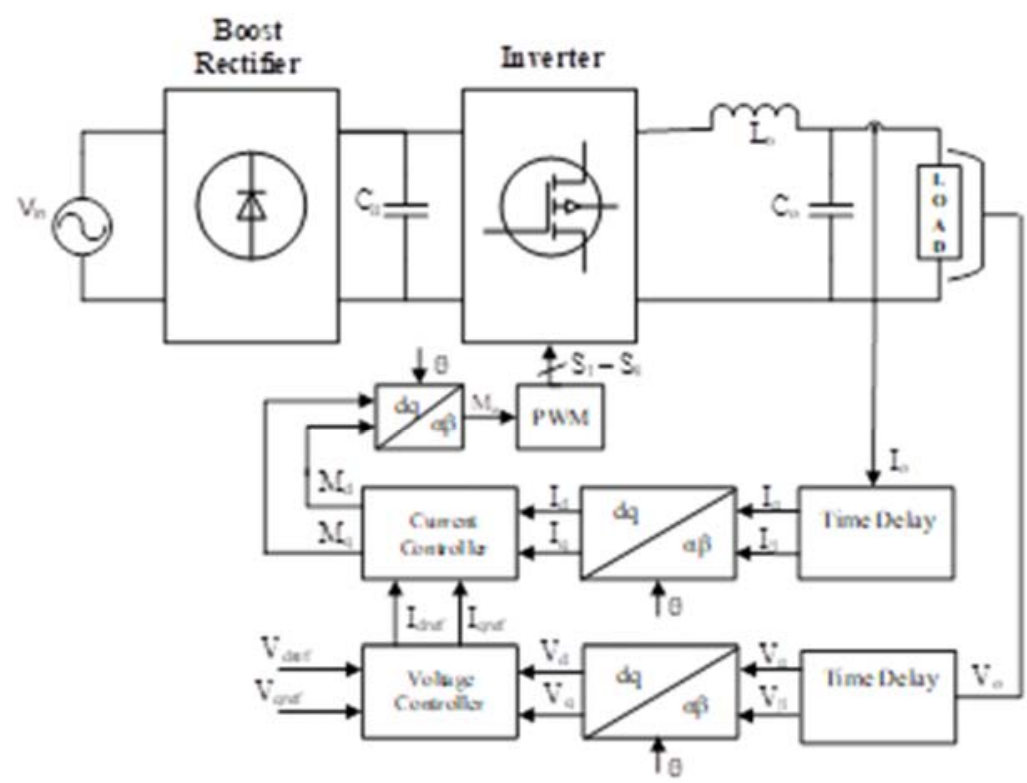

Figure 4. Block diagram of SRFPI controller

Hence, the modulated switching signal for the inverter is generated by applying the inverse Park transformation to the output of the current controller. Thereafter, the Pulse width modulated (PWM) signals to drive the inverter switches are obtained by comparing the modulated switching signal with a triangular carrier signal.

\section{SIMULATION AND EXPERIMENTAL RESULTS}

In this section, to verify the performance of the proposed converter, both system simulation and experimental results have been presented.

\subsection{Simulation Results}

The simulation is conducted using the MATLAB/SIMULINK tool; Figure 5 depicts the simulation model of the proposed voltage-frequency converter. Simulations are performed for two different input voltages, $110 \mathrm{~V} / 60 \mathrm{~Hz}$ and $220 \mathrm{~V} / 50 \mathrm{~Hz}$.

Int J Pow Elec \& Dri Syst Vol. 10, No. 4, Dec 2019 : 2165 - 2172 


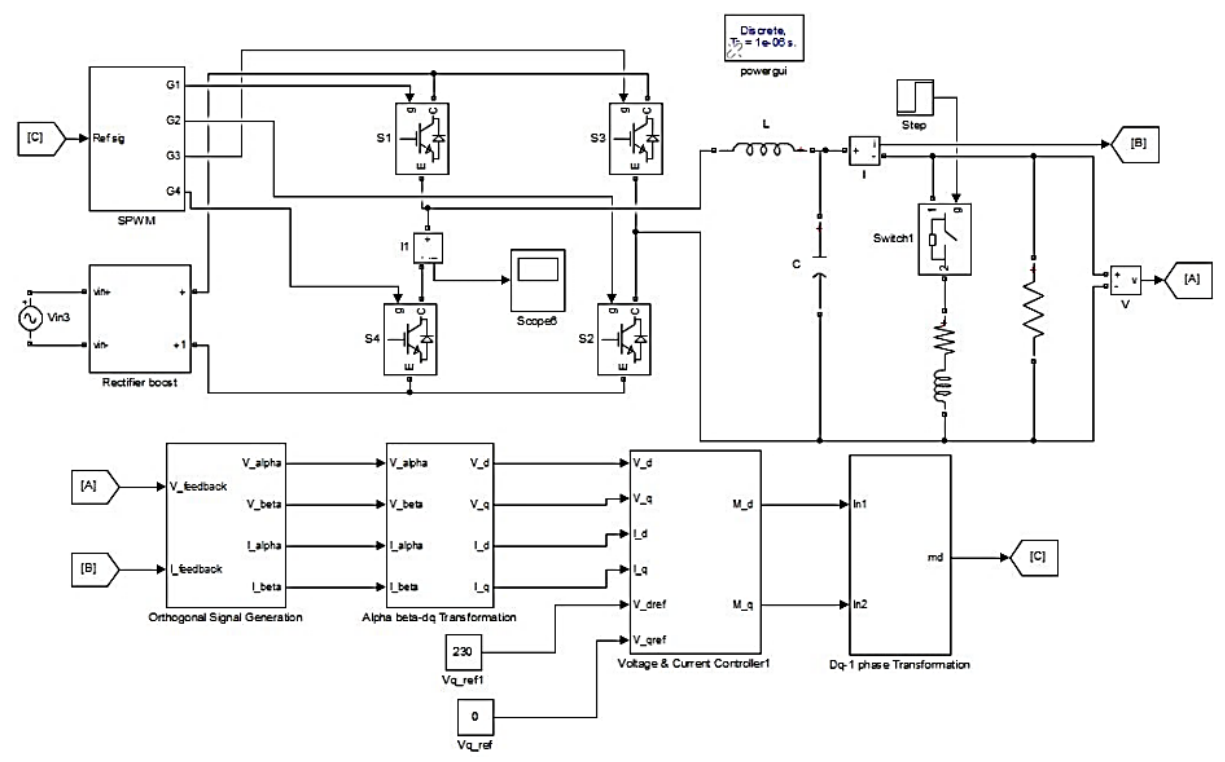

Figure 5. Simulation model of proposed converter

Figure 6 shows the output voltage waveform of various stages of the voltage-frequency converter for an input of $110 \mathrm{~V} / 60 \mathrm{~Hz}$ and a resistive load of $100 \Omega$.

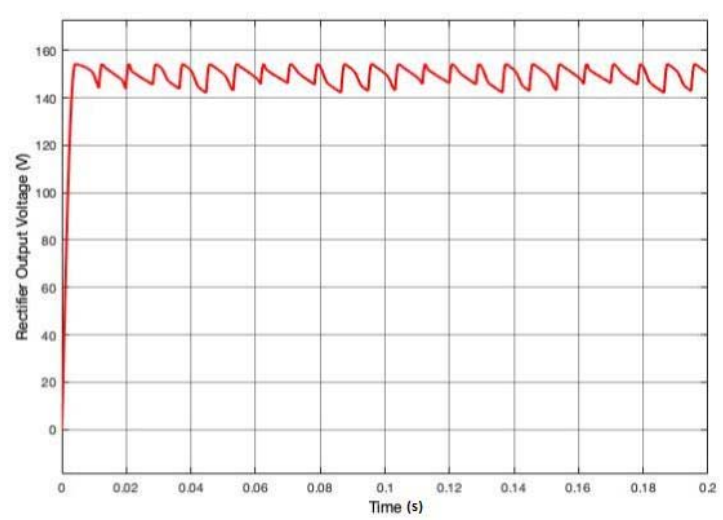

(a)

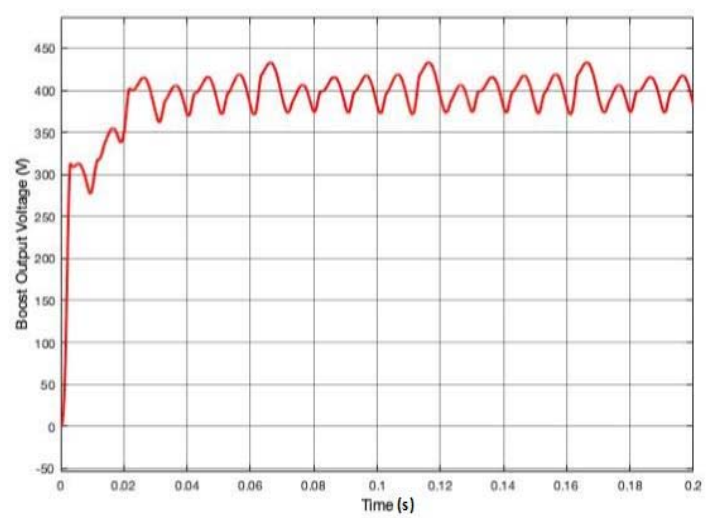

(b)

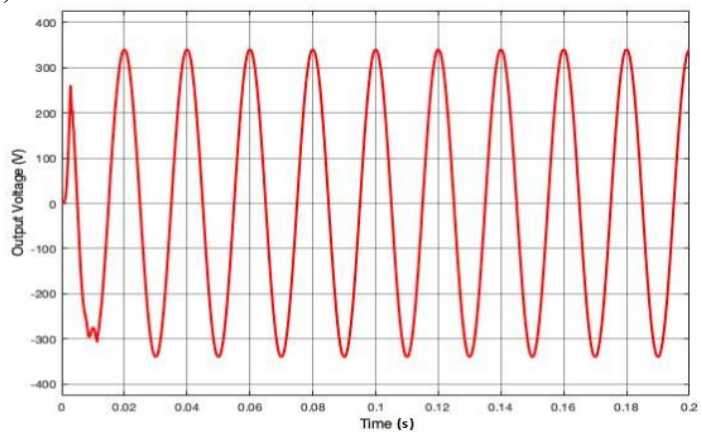

(c)

Figure 6. Simulation results for the proposed converter for an input voltage of $110 \mathrm{~V}_{\text {rms. }}$ (a) Rectifier output voltage. (b) Boost converter output voltage. (c) Inverter output voltage. 
Figure 6(a) shows the output waveform of the rectifier where the $110 \mathrm{~V}_{\text {rms }}$ is converted into $156 \mathrm{~V}$ DC. The voltage is then stepped up to $400 \mathrm{~V} \mathrm{DC}$ in the boost stage, and the waveform obtained is shown in Figure $6(\mathrm{~b})$. Figure $6 \mathrm{c}$ presents the output waveform at the inverter stage where the DC link voltage is converted back into $220 \mathrm{~V} \mathrm{AC}$ with a frequency of $50 \mathrm{~Hz}$. It is clear that the steady-state error in the output voltage is negligibly small.

Figure 7 shows the output voltage waveforms for an input of $220 \mathrm{~V} / 50 \mathrm{~Hz}$. After rectification, the DC voltage is converted directly into $110 \mathrm{~V}_{\text {rms }}$ with a frequency of $60 \mathrm{~Hz}$ as shown in Figure 7(b). Because the rectifier provides the required DC link voltage for the inverter operation, the boost stage is omitted here.

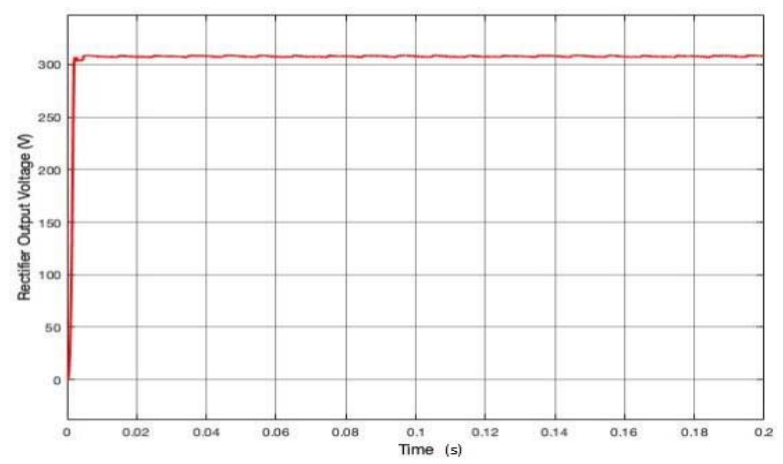

(a)

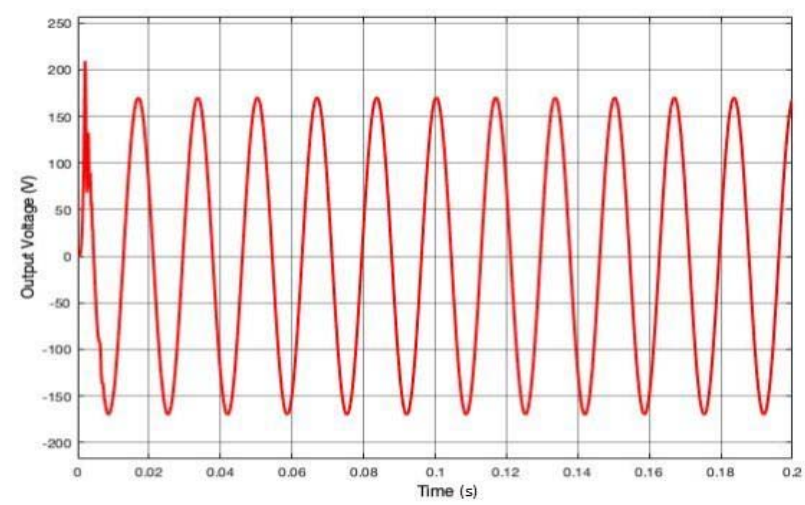

(b)

Figure 7. Simulation results for the proposed converter for an input voltage of $220 \mathrm{~V}_{\text {rms. }}$. (a) Rectifier output voltage. (b) Inverter output voltage.

\subsection{Experimental Results}

The proposed voltage-frequency converter system was set up in a laboratory. The overall system can be divided into two parts, namely the power circuit and the control circuit. The power circuit consists of a low power DC source, full bridge rectifier module, boost circuit, inverter circuit, LC filter, and sensors. The control circuit comprises the driver circuits and microcontroller for performing the control algorithms. The control algorithm was implemented on the Arduino Mega 2560 microcontroller board, which is based on the ATmega2560 processor. It is a low-cost microcontroller that can act as an interfacing component between software and hardware components. The gate signals for the boost converter and the inverter are generated through an inbuilt PWM module of the microcontroller. The signal generated from simulink is uploaded to the microcontroller chip. As the library for the Arduino is available in MATLAB, the mathematical control algorithm can be developed more easily. Arduino provides the advantages of low cost, simplicity, and a clear programming environment. Table 1 lists the ratings of the inductors and capacitors used to develop the experimental prototype.

Int J Pow Elec \& Dri Syst Vol. 10, No. 4, Dec 2019 : 2165 - 2172 
Table 1: Experimental Parameters

\begin{tabular}{cc}
\hline Parameters & Value \\
\hline Input Inductance & $1.5 \mathrm{mH}$ \\
Output Inductance & $350 \mu \mathrm{H}$ \\
Input capacitance & $3000 \mu \mathrm{F}$ \\
DC link capacitance & $100 \mu \mathrm{F}$ \\
Output capacitance & $60 \mu \mathrm{F}$ \\
\hline
\end{tabular}

The experimental waveforms at the rectifier, boost, and inverter stages of the proposed converter are shown in Figure 8.

[40 V/div]

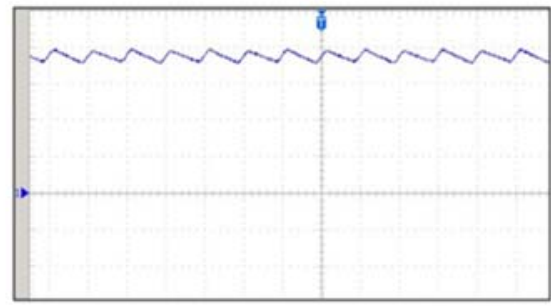

Time [10 ms div]

(a)

[100 V/div]

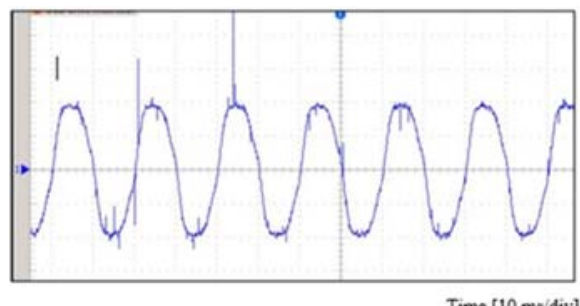

(c)
[100 V/div]

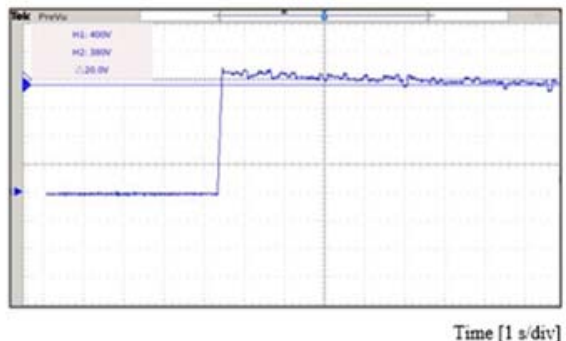

(b)

[80V/div]

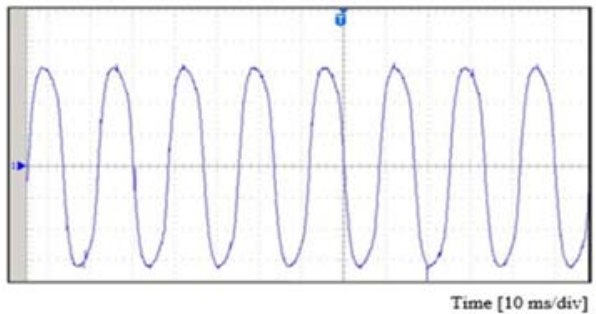

(d)

Figure 8. Experimental results for the proposed converter for an input voltage of $110 \mathrm{~V}_{\text {rms. }}$. (a) rectifier output voltage (b) boost converter output voltage. (c) Inverter output voltage without snubber. (d) Inverter output voltage with snubber

Figure 8(a) shows the rectified voltage for an input of $110 \mathrm{~V}_{\mathrm{rms}}$ feeding a $1000 \mu \mathrm{F}$ capacitor. From the waveforms, it is observed that that the ripple factor obtained is $\pm 5.3 \%$ on each side, which is within acceptable limits. Figure 8(b) depicts the boost converter output voltage; Figures. 8(c) and 8(d) represent the inverter output voltage. Here, an RC snubber network is utilized to control the voltage transients caused by the fast switching of the MOSFET. It can be seen that the inverter output voltage remains sinusoidal with only a small distortion observable when it starts conducting. Furthermore, it is clear that all experimental results are in good agreement with the simulation results.

\section{CONCLUSIONS}

This paper has proposed a simple and a compatible portable voltage-frequency converter for low power applications. The converter ensures the proper functioning of personal electrical appliances whilst traveling, providing the voltage and frequency specified on the device. An SRFPI controller is adopted to regulate the system frequency and instantaneous output voltage. Moreover, to simplify the tuning of the PI controller parameters, the LSA optimization algorithm is employed, thereby reducing the steady state error and hence improving the controller performance. In addition, simulations and laboratory experiments confirm the effectiveness of the proposed converter. Control algorithm was implemented on the Arduino Mega microcontroller board that interfaces between Simulink model and the hardware prototype. The experimental result has shown that the proposed system has satisfactory output voltage control under different input 
voltages with a ripple factor of $\pm 5 \%$, which is in acceptable limit. However, to achieve better performance for a wide range of input voltages, SRFPI controller used in the proposed system can be improved with advanced control techniques, that form a plan for future research.

\section{ACKNOWLEDGEMENT}

This work was supported by the United Arab Emirates University (UAEU) under Grant 31N348167 SURE+2018

\section{REFERENCES}

[1] E. R. Ronan, et al., "A power electronic based distribution transformer," IEEE Power Engineering Review, vol. 22, no. 3, pp. 61, Mar 2002.

[2] C. Rosa, et al., "A transformerless power electronic converter topology for PDLC applications." 9th International Conference on Compatibility and Power Electronics, pp. 359-363, 2015.

[3] P. Ziogas, et al., "Optimum system design of a three phase rectifier-inverter type of frequency changer," IEEE Transactions on Industrial Applications, vol. IA-21, no. 5, pp. 1215-1225, 1985.

[4] R. Ortega, et al., "Control techniques for reduction of the total harmonic distortion in voltage applied to a singlephase inverter with nonlinear loads: Review," Renewable and Sustainable Energy Reviews, vol. 16, no. 3, pp. 1754-1761, Apr 2012.

[5] J. Argo, et al., "A control method for single phase PWM inverters," 4th IEEE International Conference on Power Electronics and Drive Systems, pp. 282-285, 2001.

[6] P. Mattavelli, et al., "An improved dead-beat control for UPS using disturbance observers," IEEE Trans. Ind. Electron., vol. 52, no. 1, pp. 206-212, Feb.2005

[7] A. Abrishamifar, et al., "Fixed switching frequency sliding mode control for single-phase unipolar inverters", IEEE Transactions on Power Electronics, vol. 27, no. 5, pp. 2507-2514, Nov 2011.

[8] J. Matas, et al., "A discrete sliding mode control of a buck-boost inverter," IEEE, 2002, pp. 140-144.

[9] K. Zhou, et al., "Zero-phase odd-harmonic repetitive controller for a single-phase PWM inverter," IEEE Transactions on Power Electronics, vol. 21, no. 1, pp. 193-201, Jan 2006.

[10] M. J. Ryan and R. D. Lorenz, "A synchronous-frame controller for a single-phase sine wave inverter," Proceedings of APEC 97-Applied Power Electronics Conference, pp. 813-819, 1997.

[11] A. Roshan, et al., "A D-Q frame controller for a full-bridge single phase inverter used in small distributed power generation systems," APEC 07-Twenty-Second Annual IEEE Applied Power Electronics Conference and Exposition, pp. 641-647, 2007.

[12] M. Monfrared, et al., "Analysis, Design, and Experimental Verification of a Synchronous Reference Frame Voltage Control for Single-Phase Inverters," IEEE Trans. Ind. Electron., vol. 61, no. 1, pp. 258 -269, Jan 2014.

[13] D. Dong, et al., "On zero steady-state error voltage control of single-phase PWM inverters with different load types," IEEE Trans. Power Electron., vol. 26, no. 11, pp. 3285- 3297, Nov 2011.

[14] L. Yun, et al., "PID control system analysis and design," IEEE Control Systems Magazine, vol. 26, pp. 32-41, Feb 2006.

[15] P. V. Goppi, et al., "Model based tuning of PID controller," Journal of Control and Instrumentation, vol. 4, no. 1, 2229-6972, Jan 2013.

[16] B. Nagraj, et al.," Tuning algorthims for PID controller using soft computing techniques, ” International journal of computer science and network theory, vol .08, no. 6, pp 140-145, April 2008.

[17] G. Arunkumar, et al., "Parameter optimization of three phase boost inverter using genetic algorithm for linear loads,"Energy Procedia, vol. 90, pp. 559-565, Dec 2016.

[18] T. H. Kim, et al., "Robust PID controller tuning based on the constrained particle swarm optimization,"Automatica, vol. 44, no. 4, pp. 1104-1110, Apr 2008.

[19] N. T. Nguyen and H. H. Lee, "Fuzzy PI Controller for Grid-Connected Inverters," International Conference on Intelligent Computing, pp. 300-308, 2011.

[20] S. M. Ayob, et al., "Inverter Control using A Simplified Fuzzy PI Controller," IET International Conference on Power Electronics, Machines and Drives, pp.19 -21, April 2010.

[21] H. Shareef, et al., "Lightning search algorithm," Applied Soft Computing, vol. 36, pp. 315-333, Nov 2015.

[22] H. Shareef, et al., "A Nature Inspired Heuristic Optimization Algorithm Based on Lightning," Third International Conference on Artificial Intelligence, Modeling and Simulation, pp. 9-14, 2015.

[23] M. Asna, et al., "Analysis and design of single phase voltage-frequency converter with optimized PI controller," International Journal of Power Electronics and Drive Systems, vol. 10, no. 1, pp. 522-529, Mar 2019.

[24] S. A. Zulkifli, et al., "MATLAB-Arduino as a low cost microcontroller for 3 phase inverter," IEEE Student Conference on Research and Development, pp. 1-5, 2014.

[25] N. M. Abdel-Rahim and J. E. Quaicoe, "Analysis and design of a multiple feedback loop control strategy for single-phase voltage-source UPS inverters," IEEE Transactions on Power Electronics, vol. 11, pp. 532-541, July 1996.

Int J Pow Elec \& Dri Syst Vol. 10, No. 4, Dec 2019 : 2165 - 2172 